\title{
Effectiveness of Low Cost Laparoscopic Training Box to Increase Laparoscopic Skills in Urology Training Center Universitas Padjadjaran/Hasan Sadikin General Hospital
}

\author{
Aaron Tigor Sihombingi,2, Jupiter Sibarani' ${ }^{1}$, Sudigdo Adi ${ }^{2}$ \\ ${ }^{1}$ Urology Department, Faculty of Medicine, Universitas Padjadjaran, Bandung, Indonesia \\ ${ }^{2}$ Postgraduate School of Medicine, Universitas Padjadjaran, Bandung, Indonesia \\ Email: aaron2605@gmail.com
}

How to cite this paper: Sihombing, A.T., Sibarani, J. and Adi, S. (2017) Effectiveness of Low Cost Laparoscopic Training Box to Increase Laparoscopic Skills in Urology Training Center Universitas Padjadjaran/ Hasan Sadikin General Hospital. Open Access Library Journal, 4: e3412.

https://doi.org/10.4236/oalib.1103412

Received: January 29, 2017

Accepted: March 11, 2017

Published: March 14, 2017

Copyright $\odot 2017$ by authors and Open Access Library Inc.

This work is licensed under the Creative Commons Attribution International License (CC BY 4.0).

http://creativecommons.org/licenses/by/4.0/

\section{(c) (i) Open Access}

\begin{abstract}
Laparoscopy has become the standard of care in many urological procedures. Various simulations are used to train laparoscopic skills. This study evaluates the effectiveness of our low cost laparoscopic training box simulation to improve urologic laparoscopic skills. The study was conducted during Urology Laparoscopic Surgery Training Course in the department of Urology Universitas Padjadjaran/Hasan Sadikin General Hospital in year 2016. Eight practicing urologists with mean age 40.2 completed the study. Lecture and video presentation were presented to all participants before box training. Pretraining participants were evaluated for two basic laparoscopic tasks using a global rating scale and a task specific checklist. Participants then were trained under instructor supervision and then evaluated using the same global rating scale and specific task list. Participants performed nephrectomy on the second day on a live animal (pigs) and evaluated. Wilcoxon matched paired signedrank test was used to analyze pre- and post-training score results. There are statistically significant improvements in global rating scale and task specific checklist for both tasks $(P<0.05)$. All participants successfully performed nephrectomy on the pigs that reflects low cost laparoscopic training box simulation is effective to improve urologic laparoscopic skills.
\end{abstract}

\section{Subject Areas \\ Urology}

\section{Keywords}

Laparoscopy, Low Cost Training Box 


\section{Introduction}

With the advancement in surgical technology, laparoscopic surgery has become the standard in many urological procedures. Laparoscopy has the ability to minimize surgical trauma, decrease postoperative surgical pain, reduce the length of the hospital stay, and provide a safe and esthetically surgical wound. In renal cancer treatment for instance, laparoscopy radical nephrectomy has replaced open radical nephrectomy as the standard for renal cancer total removal [1]. Other procedure in which laparoscopy has become a standard is laparoscopic deroofing for renal cyst. Current evidence on the safety and efficacy of laparoscopic deroofing of simple renal cysts is adequate to support the use of this procedure [2].

In Indonesia laparoscopy urologic surgery is not widely distributed. This is primarily due to high cost and advanced technologies require organizing laparoscopy training course. There are only three centers in Indonesia that have facility to organize laparoscopic urology training course. The course is only held once a year and some of the equipments for the laparoscopic urology training are rotated from center to center. Also there is no formal fellowship available for laparoscopic urologic training in Indonesia.

One of the problems for widespread use of laparoscopy surgery in Indonesia is a steep learning curve in laparoscopic surgery. The learning curve for laparoscopy radical prostatectomy ranged from 250 to 750 cases [3]. In laparoscopy pyeloplasty the learning curve reached a plateau after 51 cases [4].

In order to shorten the laparoscopic learning curve, various simulations from simple box trainer, animal and virtual reality simulator are used. Virtual reality system is an advanced and effective training method which has been proved to significantly improve performance in the operation room compared to the control group [5]. Similarly, simple box training improves technical skills compared with no training in trainees without previous laparoscopic experience [6].

Laparoscopy simulation system is expensive to most Indonesian, thus it is not targeted for use by trainer outside of training facilities. However, given a low budget for education system, limited training center and the growing demand in laparoscopy training, a low-cost and effective simulation system is needed.

Urology department Universitas Padjadjaran has designed a low-cost training box for laparoscopy simulation training. The objective of this study is to evaluate the effectiveness of our low-cost training box designed to improve laparoscopic urology skills.

\section{Material and Method}

This study was carried out during three days course of $2^{\text {nd }}$ Indonesia Japan Collaboration Program for Urology Laparoscopic Surgery Training Course in the department of Urology Universitas Padjadjaran/Hasan Sadikin General Hospital in year 2016. Hasan Sadikin general hospital is a tertiary hospital in Indonesia with three hundred and seventy four medical doctors and thirty four thousand 
admission per year. Ethical permission from Hasan Sadikin general hospital ethical committee was taken before the commencemment of the study

All hands on training laparoscopy participants, who are practicing urologist, are included in this study.

The department of urology Universitas Padjadjaran has set up a training room contain with six training box (Figure 1). Lectures consisting of basic instrument in laparoscopy surgery, basic techniques in laparoscopy surgery, suturing and knotting, and video presentation were presented before box training session. Box training demonstration is performed by instructor for each task. Three hours supervised box training session with one candidate held the camera for the other participant to feel of how camera is important in laparoscopic surgery. Participants performed 4 tasks in the following order : first task transferring peanut to a small rubber bag; second task inserting stent to a hole on a straw; third task pattern cutting; fourth task suturing and knotting (Figure 2). On the second day all participants were performing nephrectomy on a pig.

Locally manufactured box-trainer fitted with rubber gaskets to accommodate cannulae for the scope and tools (Figure 3). A camera equipment and a fiberoptic light source was used and the image is displayed on a video monitor.

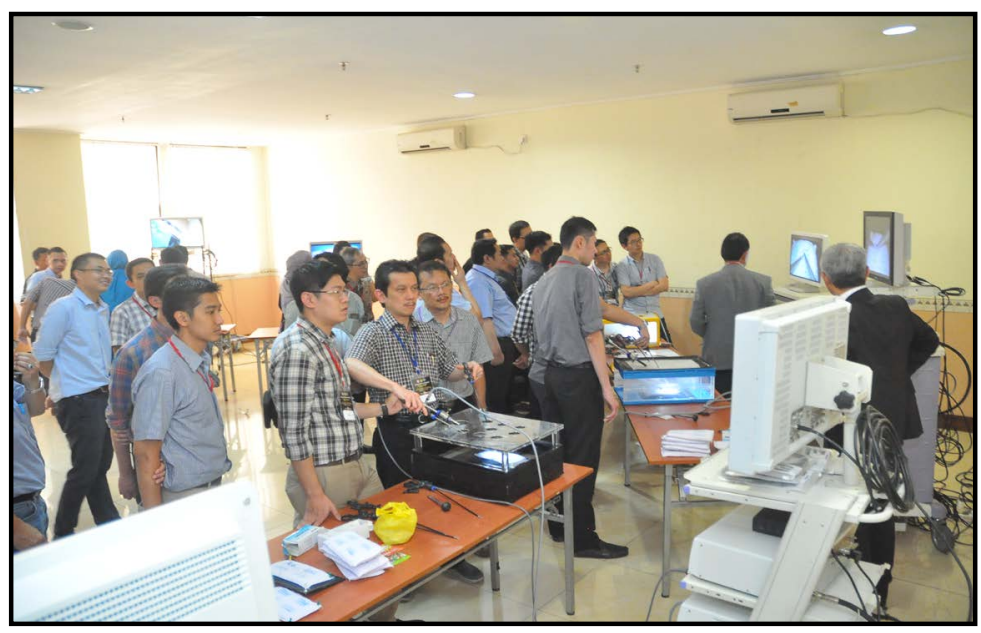

Figure 1. Training room.

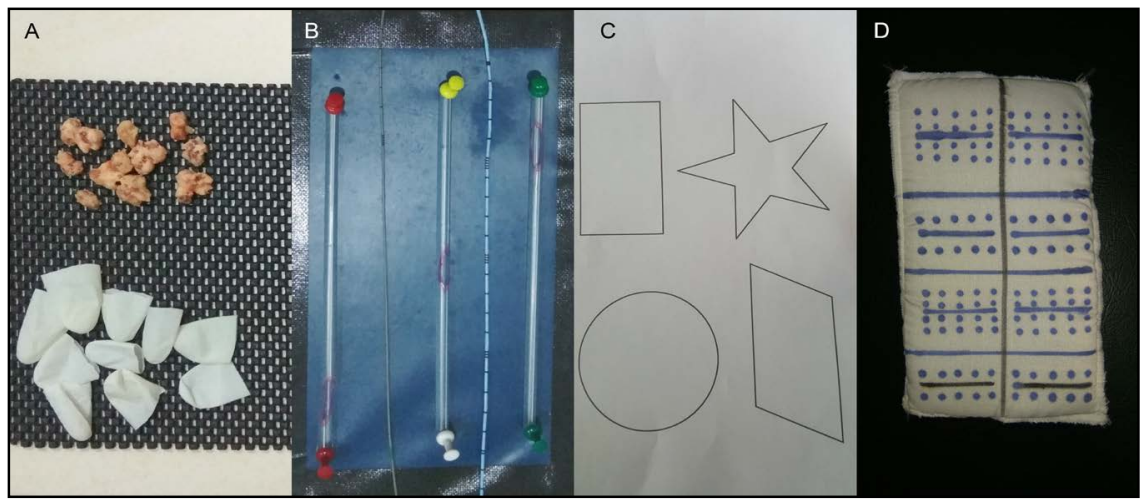

Figure 2. (A) small rubber bag and peanut; (B) straw with different side hole (arrow); (C) cutting pattern; (D) sponge marked with dot for suturing and knotting. 


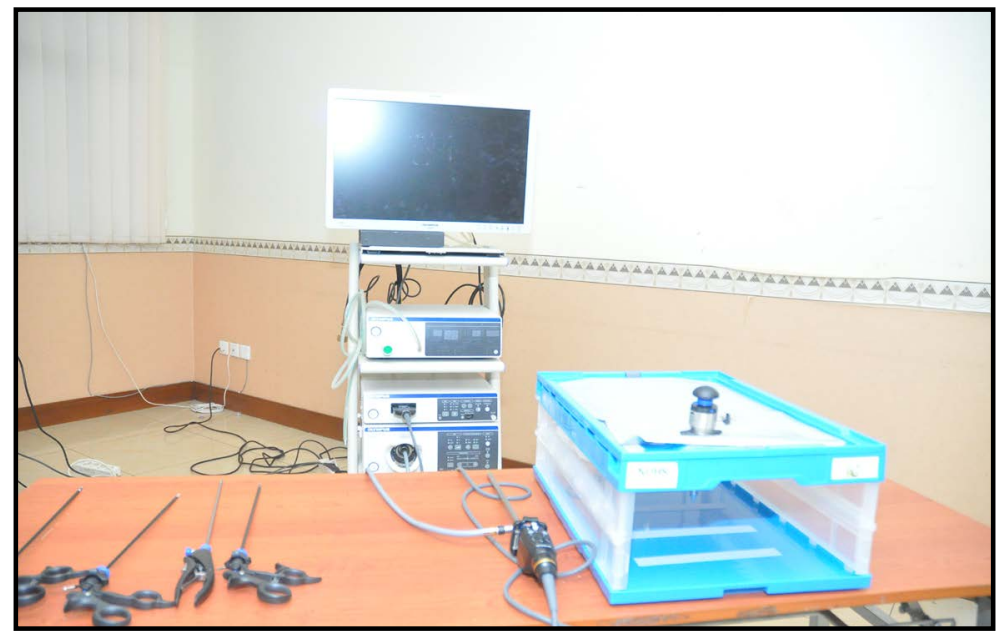

Figure 3. Locally manufactured box trainer.

\section{Pre training assesment}

Each participant was given two basic task. The assessment was done by an observer using a global rating scale (Table 1) and a task specific checklist (Table 2) [7].

The first task is to insert ureteral catheter no. 4 french (fr) to a hole on a straw without damaging or displacing the straw. There are three straws with different hole placement, one on the right side of the straw, one on the midle side of the straw and one on the left side of the hole (Figure 2(B)).

The second task is to perform suturing to a dot marked white sponge and to performed a square knot using 3-0 silk sutures with a curve needle.

\section{Post training Assesment}

After completion all course sessions, participants were asked to perform the same tasks and were assessed by the same rating scale. Wilcoxon matched paired signed-rank test is used to assessed statistical significant difference between pre course and post course scores and a $P$ value $<0.05$ is considered to statistically significant. All analysis were performed using $\mathrm{R}$, which is open source and freely available.

On the second day, the participants were divided to four groups consist of two participant each, to perform nephrectomy on a pig. One participant holding the camera and one participant performing the operation. Successful operation is considered if there is no other organ injury while performing nephrectomy and the pig is still alive after unilateral nephrectomy.

\section{Results}

There were eight urologists completed the study. All of the participant are male with mean age of 40.2 years and mean working experience 6.6 years.

The mean improvement in ureteral stent insertion score by global rating scale are listed in Table 3. Using Wilcoxon matched-paired signed-ranks test, 2-tailed $P$-value $0.01391(P<0.05)$ which is statistically significant.

The mean improvement in suture drill score by global rating score are listed 
Table 1. Global rating scale (Maximum score 20).

\begin{tabular}{|c|c|c|c|c|c|}
\hline \multicolumn{6}{|c|}{ Rating } \\
\hline Variable & 1 & 2 & 3 & 4 & 5 \\
\hline Time and motion & Many unnecessary & & $\begin{array}{l}\text { Efficient time and motion, } \\
\text { but some unnecessary moves }\end{array}$ & & $\begin{array}{l}\text { Economy of movement } \\
\text { and maximum efficiency }\end{array}$ \\
\hline $\begin{array}{l}\text { Instrument } \\
\text { handling }\end{array}$ & $\begin{array}{l}\text { Repeatedly makes tentative or } \\
\text { awkward moves with instruments }\end{array}$ & & $\begin{array}{l}\text { Competent use of instruments, } \\
\text { although occasionally } \\
\text { appeared stiff or awkward }\end{array}$ & & $\begin{array}{l}\text { Fluid moves with } \\
\text { instruments and } \\
\text { no awkwardness }\end{array}$ \\
\hline $\begin{array}{l}\text { Knowledge } \\
\text { of instruments }\end{array}$ & $\begin{array}{l}\text { Frequently asked for the wrong } \\
\text { instrument or used } \\
\text { inappropriate instrument }\end{array}$ & & $\begin{array}{l}\text { Knew the names of most } \\
\text { instruments and used appropriate } \\
\text { instrument for the task }\end{array}$ & & $\begin{array}{l}\text { Obviously familiar with the } \\
\text { instruments required } \\
\text { and their names }\end{array}$ \\
\hline Use of assistants & $\begin{array}{l}\text { Consistently placed assistants poorly } \\
\text { or failed to used assistants }\end{array}$ & & $\begin{array}{l}\text { Good use of assistants } \\
\text { most of the time }\end{array}$ & & $\begin{array}{l}\text { Strategically used assistant to } \\
\text { the best advantage at all times }\end{array}$ \\
\hline
\end{tabular}

Table 2. Task specific checklist. One point for each correctly performed procedure.

\begin{tabular}{|c|c|c|}
\hline Procedure & Correctly performed & Incorectly performed \\
\hline \multicolumn{3}{|l|}{ Proper straw handling } \\
\hline \multicolumn{3}{|l|}{ Proper stent insertion } \\
\hline \multicolumn{3}{|l|}{ Correct needle holding tehnique } \\
\hline \multicolumn{3}{|l|}{ Accurate needle passage } \\
\hline Square knot & & \\
\hline
\end{tabular}

Table 3. Participant characteristic.

\begin{tabular}{cccc}
\hline No. & Age (years) & Gender & Working experience (years) \\
\hline 1 & 39 & Male & 6 \\
2 & 47 & Male & 12 \\
3 & 55 & Male & 18 \\
4 & 46 & Male & 11 \\
5 & 36 & Male & 3 \\
6 & 33 & Male & 1 \\
7 & 33 & Male & 1 \\
8 & 33 & Male & 1 \\
\hline
\end{tabular}

in Table 4. Using Wilcoxon matched-paired signed-ranks test, 2 -tailed $P$-value $0.0136(P<0.05)$ which is statistically significant.

The mean improvement in task check list is listed in Table 5. Using Wilcoxon matched-paired signed-ranks test, 2-tailed $P$-value $0.0132(P<0.05)$ which is statistically significant.

All four groups (two participants each, one participant holding the camera and one participant performing the operation) performed succesfull nephrectomy procedure. There was no other organ injury and the pigs alive (Table 6). 
Table 4. Global rating scale (Maximum score 20).

\begin{tabular}{ccc}
\hline & Pre-training score & Post-training score \\
\hline Mean & 7.6 & 12.5 \\
Standard deviation & 3.3 & 1.2 \\
Median & 7 & 12 \\
\hline
\end{tabular}

Using Wilcoxon matched-paired signed-ranks test, 2-tailed $P$-value 0.01391 .

Table 5. Mean pre and post training global rating scale in suturing and knotting.

\begin{tabular}{ccc}
\hline & Pre-training score & Post-training score \\
\hline Mean & 6.7 & 10.3 \\
Standard deviation & 3.0 & 2.0 \\
Median & 5.5 & 9.5 \\
\hline
\end{tabular}

Using Wilcoxon matched-paired signed-ranks test, 2-tailed $P$-value 0.0136 .

Table 6. Mean pre-training and post training task checklist.

\begin{tabular}{ccc}
\hline & Pre-training score & Post-training score \\
\hline Mean & 7.6 & 12.5 \\
Standard deviation & 3.3 & 1.2 \\
Median & 7 & 12 \\
\hline
\end{tabular}

Using Wilcoxon matched-paired signed-ranks test, 2-tailed $P$-value 0.0132 .

\section{Discussion}

In 1990 laparoscopy surgery was introduced to Indonesian general surgeons. A teleconference between American surgeon and Indonesian was held in Indonesia private hospital. It was followed by laparoscopy cholecystectomy live surgery demonstartion in two private hospitals in the capital city of Indonesia Jakarta. Since then laparascopy cholecystectomy has gradually become a gold standard for treating gallbladder disease in several major cities in Indonesia.

Laparoscopy urology in Indonesia was started in 2004 when five Indonesian urologists were sent for laparoscopy training in Salzbourg, Austria. In contrast to laparascopy cholecystectomy there was not such a relatively easy to learn and frequent procedure in urology. Also the center for laparoscopy urology training in Indonesia has not changed since 2004. This is due to cost for building a laparoscopy center. Thus the widespread use of laparoscopy urology in Indonesia is very slow.

Study by Gawande et al. [8] showed that $66 \%$ of all adverse events in Colorado and Utah hospital were surgical and $54 \%$ of these surgical adverse events were preventable. These findings showed that there is a need for a quality improvement in surgical care.

Indonesian research and higher education ministry in 2013 planned to shorten urology training time from 5 years training to 4 years training to fasten urology spreading in Indonesia. However, these plans will reduce the opportu- 
nities for trainee urologists to learn their skills through experience in the operating room and reduce quality surgical care.

Simulation offered a promising training environment for intraoperative stress management, enhancing performance and patient safety [9]. Evidence suggests that skills acquired in the simulated environment may transfer to the clinical setting [10]. However, for a simulation to be integrated into any training curriculum, it must be shown that it is effective and efficient (low cost and reducing training time).

Our box training simulation was designed to improve basic skills. Ureteral catheter insertion to a hole in a straw was designed to improve instrument handling, two dimensional image orientation, depth perception and hand-eye coordination.

One of the most challenging skills to gain in laparascopy is tissue anastomosis. Suturing drill in our laparascopy training box, the participants were asked to place stich to a sponge marked with dot using 3-0 silk suture with a curve needle. Attention was paid on tracing, needle holding, taking proper bites, accuracy puncture needle to the dot, tying a knot and cutting off extra suture.

P.D. van Hove et al. [11] review and analyze studies addressing the validity and reliability of methods for objective skills assessment within surgery and gynaecology. There were 104 studies and these studies were assessed according to the Oxford Centre for Evidence-Based Medicine levels of evidence. They concluded that most methods of skills assessment are valid for feedback or measuring progress of training.

This study used a global rating scale and task specific check list. Both of the measurement showed statistically significant improvement in laparoscopy performance in the box training simulation.

Studies by Martin et al. [12] and Beard et al. [13] correlate performance in bench tasks with performance in live animals (pigs) and the operating room. These studies found that there were correlation between performance in bench task and performance in live animal and operating rooms.

In our study there were improvements in both global rating scale and task specific check list in all participants and all groups successfully performed nephrectomy on pigs. Limitation of our study is the low number of participant and all participants are practicing urologists who have working experience at least one year.

Based on this study, we can conclude that our low cost training box is effective as a simulator to improve laparoscopic skills for urologist.

\section{References}

[1] Berger, A., Brandina, R., Atalla, M.A., et al. (2009) Laparoscopic Radical Nephrectomy for Renal Cell Carcinoma: Oncological Outcomes at 10 Years or More. The Journal of Urology, 182, 2172-2176. https://doi.org/10.1016/j.juro.2009.07.047

[2] Consonni, P., Nava, L., Scattoni, V. and Bianchi, A. (1996) Percutaneous EchoGuided Drainage and Sclerotherapy of Symptomatic Renal Cysts: Critical Comparison with Laparoscopic Treatment. The Archives of Italian Urology and Andrology, 
68, 27-30.

[3] Hammid, A., Mohammed, S.K., Khurshid, A.G., et al. (2014) Learning Curves for Urological Procedures: A Systematic Review. BJU International, 114, 617-629. https://doi.org/10.1111/bju.12315

[4] Naya, Y., Araki, K., Kaga, K., et al. (2011) Learning Curve of Laparoscopic Pyeloplasty with 51 Cases by a Single Surgeon. Journal of Endourology, 25, 216-217.

[5] Grantcharov, T.P., Kristiansen, V.B., Bendix, J., Bardram, L., Rosenberg, J. and Funch-Jensen, P. (2004) Randomized Clinical Trial of Virtual Reality Simulation for Laparoscopic Skills Training. The British Journal of Surgery, 91, 146-150. https://doi.org/10.1002/bjs.4407

[6] Nagendran, M., Toon, C.D., Davidson, B.R. and Gurusamy, K.S. (2014) Laparoscopic Surgical Box Model Training for Surgical Trainees with No Prior Laparoscopic Experience. Cochrane Database of Systematic Reviews, 17, CD010479.

[7] Moorthy, K., Munz, Y., Sarker, S.K. and Darzi, A. (2003) Objective Assessment of Technical Skills in Surgery. British Medical Journal, 327, 1032-1037.

https://doi.org/10.1136/bmj.327.7422.1032

[8] Gawande, A.A., Thomas, E.J., Zinner, M.J. and Brennan, T.A. (1999) The Incidence and Nature of Surgical Adverse Events in Colorado and Utah in 1992. Surgery, 126, 66-75. https://doi.org/10.1067/msy.1999.98664

[9] Arora, S., Sevdalis, N., Nestel, D., Tierney, T., Woloshynowych, M. and Kneebone, R. (2009) Managing Intraoperative Stress: What Do Surgeons Want from a Crisis Training Program? The American Journal of Surgery, 197, 537-543. https://doi.org/10.1016/j.amjsurg.2008.02.009

[10] Issenberg, S.B., Mc Gaghie, W.C., Petrusa, E.R., Lee Gordon, D. and Scalese, R.J. (2005) Features and Uses of High-Fidelity Medical Simulations That Lead to Effective Learning: A BEME Systematic Review. Medical Teacher, 27, 10-28. https://doi.org/10.1080/01421590500046924

[11] Van Hove, P.D., Tuijthof, G.J., Verdaasdonk, E.G., Stassen, L.P. and Dankelman, J. (2010) Objective Assessment of Technical Surgical Skills. The British Journal of Surgery, 97, 972-987. https://doi.org/10.1002/bjs.7115

[12] Martin, J.A., Regehr, G., Reznick, R., MacRae, H., Murnaghan, J., Hutchison, C., et al. (1997) Objective Structured Assessment of Technical Skill (OSATS) for Surgical Residents. The British Journal of Surgery, 84, 273-278.

[13] Beard, J.D., Jolly, B.C., Newble, D.I., Thomas, W.E., Donnelly, J. and Southgate, L.J. (2005) Assessing the Technical Skills of Surgical Trainees. The British Journal of Surgery, 92, 778-782. https://doi.org/10.1002/bjs.4951 
Submit or recommend next manuscript to OALib Journal and we will provide best service for you:

- Publication frequency: Monthly

- 9 subject areas of science, technology and medicine

- Fair and rigorous peer-review system

- Fast publication process

- Article promotion in various social networking sites (LinkedIn, Facebook, Twitter, etc.)

- Maximum dissemination of your research work

Submit Your Paper Online: Click Here to Submit

Or Contact service@oalib.com 